\title{
Elaboração e validação de manual para técnicas básicas de curso técnico em enfermagem
}

\author{
Preparation and validation of manual for basic techniques of technical course in nursing \\ Elaboración y validación de manual de técnicas básicas de curso técnico en enfermería
}

Mirtson Aécio dos Reis Nascimento ${ }^{1 *}$, Luciana Marques Andreto.

\section{RESUMO}

Objetivo: Construir e validar um manual para o componente curricular, "técnicas básicas", de curso técnico em enfermagem, fundamentado em aprendizagem baseada em problemas. Métodos: Pesquisa metodológica, seguindo as etapas: levantamento bibliográfico, construção do manual, validação do conteúdo, adequação do manual, validação semântica, adequações no manual. Participaram da validação de conteúdo 10 enfermeiros, utilizou-se a técnica Delphi, por meio de escala tipo likert. Na avaliação semântica, participaram 17 estudantes de curso técnico em enfermagem, os dados foram coletados por meio de questionário do tipo likert. A análise dos dados foi feita através do Índice de Validade de Conteúdo (IVC). Resultados: O manual construído é fundamentado em ABP, tem 45 páginas e 13 capítulos que abordam conteúdos pertinentes a "técnicas básicas", através da apresentação dos objetivos de aprendizagem, seguidos da situação- problema que abrange um ou mais conteúdos do referido componente curricular. $O$ material apresentou IVC global entre os juízes de $97,68 \%$. Quanto ao público-alvo o IVC global foi de $99,46 \%$. Conclusão: A versão final do material é válida quanto à aparência e conteúdo e pode ser utilizado no contexto ao qual se aplica.

Palavras-chave: Educação em enfermagem, Aprendizagem baseada em problemas, Estudos de validação.

\begin{abstract}
Objective: Build and validate a manual for the curricular component, "basic techniques", of a technical course in nursing, based on problem-based learning. Methods: Methodological research, following the steps: bibliographic survey, construction of the manual, content validation, adequacy of the manual, semantic validation, adjustments in the manual. 10 nurses participated in the content validation, using the Delphi technique, using a likert-type scale. In the semantic evaluation, 17 students of a technical course in nursing participated, the data were collected through a likert type questionnaire. Data analysis was performed using the Content Validity Index (CVI). Results: The built manual is based on PBL, has 45 pages and 13 chapters that address content pertinent to "basic techniques", through the presentation of the learning objectives, followed by the problem situation that covers one or more contents of that curricular component. The material presented a global CVI among the judges of $97.68 \%$. As for the target audience, the overall CVI was $99.46 \%$. Conclusion: The final version of the material is valid in terms of appearance and content and can be used in the context to which it applies.
\end{abstract}

Keywords: Education nursing, Problem-based learning, Validation studies.

\section{RESUMEN}

Objetivo: Elaborar y validar un manual del componente curricular, "técnicas básicas", de un curso técnico en enfermería, basado en el aprendizaje basado en problemas. Métodos: Investigación metodológica, siguiendo los pasos: levantamiento bibliográfico, construcción del manual, validación de contenido, adecuación del manual, validación semántica, ajustes en el manual. Diez enfermeros participaron en la validación de contenido, utilizando la técnica Delphi, utilizando una escala Likert. En la evaluación semántica participaron 17 estudiantes de un curso técnico en enfermería, los datos fueron recolectados a través de un cuestionario tipo Likert. El análisis de los datos se realizó mediante el Índice de Validez de Contenido (IVC). Resultados: El manual construido está basado en ABP, tiene 45 páginas y 13 capítulos que abordan el contenido pertinente

${ }^{1}$ Faculdade Pernambucana de Saúde (FPS), Recife - PE. *E-mail: mirtson@hotmail.com 
a las "técnicas básicas", a través de la presentación de los objetivos de aprendizaje, seguido de la situación problema que cubre uno o más contenidos de ese componente curricular. El material presentó un CVI global entre los jueces del 97,68\%. En cuanto a la audiencia objetivo, el CVI global fue del 99,46\%. Conclusión: La versión final del material es válida en términos de apariencia y contenido y puede usarse en el contexto al que se aplica.

Palabras clave: Educación en enfermería, Aprendizaje basado en problemas, Estudios de validación.

\section{INTRODUÇÃO}

A história da educação profissional de saúde, no contexto da Enfermagem, mostra que a assistência de enfermagem, antes do século XX, era, em sua maior parte, prestada por uma parcela de pessoas sem preparo formal para o trabalho. Além disso, no intuito de sacramentar essas ações, muitas vezes, havia a implementação de legislação específica com o objetivo de consolidar essa realidade de saúde do país, permeada e fortemente influenciada pelo modo de produção capitalista que proporcionou distorções na prática e produção dos serviços de saúde no Brasil (BALTAZAR C, 2017; DANTAS RAS e AGUILLAR OM, 1999)

Após décadas, houve a regulamentação do exercício profissional da enfermagem, através da Lei 7.498/86. Em seu texto, considera- se técnico em enfermagem o titular do diploma ou do certificado de Técnico de Enfermagem, expedido de acordo com a legislação e registrado em órgão competente ou, em caso de curso estrangeiro, registrado ou revalidado no Brasil. Cabe a esta categoria profissional atividades auxiliares, de nível médio técnico, atribuídas à equipe de enfermagem (BRASIL, 1987).

Diante da exigência de um curso técnico específico, cada vez mais, faz- se necessário um ensino de enfermagem marcado por uma formação cidadã e integral que atenda as novas demandas do mercado, de maneira que haja a superação da visão tradicional e dicotômica entre docente e estudante. Portanto, esta transformação dos métodos de ensino aprendizagem é dinâmica e continuamente influenciada pelos contextos sociais, políticos e econômicos da sociedade (RODRIGUES CCFM, et al., 2016).

Deste modo o uso de metodologias ativas (MA) em cursos da área da saúde são justificáveis, na medida em que atendem a própria Lei de Diretrizes e Bases da Educação Nacional (LDB) e as diretrizes curriculares do curso de graduação em Enfermagem. Essas diretrizes enfatizam a importância de trabalhar metodologias nas quais os estudantes consigam associar a teoria à prática nas diversas situações laborais da enfermagem e consequentemente, avaliar e transformar a realidade na qual está inserido (SOBRAL FR e CAMPOS CJG, 2012).

Entre as MA utilizadas no contexto da área da saúde está a Aprendizagem Baseada em Problemas (ABP). Esse método de ensino foi originado na escola de medicina da Universidade McMaster, Canadá, em torno de 1960, e, por meio dele, são utilizados problemas da vida real (reais ou fictícios) para iniciar, enfocar e motivar a aprendizagem de teorias, habilidades e atitudes (ESCRIVÃO FE e RIBEIRO LRC, 2009).

Entre os conteúdos vivenciado pelos estudantes de cursos técnico em enfermagem estão aqueles que exigem o desenvolvimento de habilidades para execução de procedimentos que requerem a associação entre teoria e prática. Considerado como "Técnicas Básicas", esse componente curricular possui em seu conteúdo programático temas como: limpeza e arrumação da unidade do paciente, higienização das mãos, manuseio de material esterilizado, cuidados de higiene corporal e oral, sinais vitais, medidas antropométricas, mudança de decúbito, posições para exame, transporte do paciente, técnicas de curativos, preparo e administração de medicamentos, venóclise, cálculo de dosagem de medicamentos e soluções, cuidados com sondas e drenos, lavagem gástrica, entoróclise, preparo do corpo pós morte, registros em enfermagem, coleta de material para exames, entre outros conteúdos (IFPE, 2018).

Diante dessa descrição, observa- se que esse componente curricular é composto por assuntos essenciais ao exercício do técnico em enfermagem. Por conseguinte, abordar técnicas básicas através desse método de aprendizagem é justificável, já que, conforme Siqueira-Batista $R$ e Siqueira-Batista $R$ (2009), entre os principais aspectos da ABP estão a aprendizagem significativa, a indissociabilidade entre teoria e prática, a educação permanente e a avaliação formativa. 
De acordo com Carvalho Neto FJ, et al. (2020), a ABP permite uma experiência positiva em amplo aspecto na área da enfermagem, visto que permite uma abordagem individual e coletiva. Isso possibilita 0 desenvolvimento de habilidades, capacidade de tomada de decisões, de gestão, disseminação e descentralização de informações.

Portanto, mediante as reflexões acerca da utilização da ABP no contexto do ensino de cursos de enfermagem, verifica- se a importância de contribuições neste campo da ciência, a partir da criação de instrumentos educativos que facilitem a aplicação dessa metodologia na formação desses profissionais. Ademais, a literatura aponta uma escassez do tema, quando se trata dessa categoria profissional (TEIXEIRA JS, et al., 2017).

Deste modo, a utilização desta metodologia ativa poderá contribuir para o preparo do técnico em enfermagem, a partir das perspectivas exigidas pelo mercado de trabalho. De acordo com Sousa CEGC (2020), o uso de MA propicia a construção do saber como forma de argumentação de ideias, evolução crítica e social, portanto pode contribuir com a formação de profissionais com as características necessárias para atender as demandas do Sistema Único de Saúde e da sociedade contemporânea.

Logo, considerando a importância da utilização de ferramentas de ensino aprendizagem fundamentadas em ABP, no contexto da formação do técnico em enfermagem, o presente trabalho teve o objetivo de descrever o processo de construção e validação de conteúdo e semântica de um manual para técnicas básicas de curso técnico em enfermagem, fundamentado na metodologia da ABP.

\section{MÉTODOS}

Trata-se de um estudo metodológico de construção e avaliação de material educativo para a formação de profissionais técnicos em enfermagem. Para isso, foram realizadas a validação de conteúdo e validação semântica do constructo (SOUZA ACD, et al., 2017; MACEDO KDS, et al., 2018).

Este trabalho foi desenvolvido em 4 etapas: levantamento bibliográfico; construção de manual; validação do conteúdo por experts e avaliação semântica pelo público-alvo.

O manual foi elaborado através de um levantamento bibliográfico acerca da aprendizagem baseada em problemas e dos conteúdos pertinentes ao componente curricular "técnicas básicas", de cursos técnicos em enfermagem. A partir desse levantamento, foram elaboradas situações-problema pertinentes à conteúdos extraídos de um projeto pedagógico do referido curso, de uma instituição de ensino pública de Pernambuco.

Na terceira etapa, foram selecionados juízes enfermeiros e docentes de cursos de graduação e/ou técnico em enfermagem, para isso foi elaborada uma lista com indicações de experts através de contato prévio com pesquisadores da área de educação para o ensino da saúde, bem como coordenadores de cursos de enfermagem (médio e/ou superior) de instituições públicas e/ou privadas de Ensino.

Foram incluídos na pesquisa, os profissionais que atenderam aos critérios estabelecidos no modelo de Fehring (FEHRING R, 1994). Os juízes precisariam obter o mínimo de 6 pontos, onde foram avaliados a titulação, área de especialização, campo das produções científicas, experiências docentes e prática assistencial.

Foram excluídos os enfermeiros docentes que estivessem afastados das suas atividades laborais por motivo de doença ou licença maternidade/paternidade.

Deste modo, foram convidados 15 participantes, para os quais enviou-se por e-mail: o Termo de Consentimento Livre e Esclarecido-TCLE, Manual elaborado, Instrumento de avaliação do perfil professional e Formulário tipo Likert que foi preenchido através da ferramenta Google form®

Esse instrumento de coleta de dados foi dividido em duas partes: a primeira abordava o perfil pessoal, profissional e acadêmico dos juízes, e a segunda continha os itens específicos utilizados para avaliar o manual em cada situação-problema. Esses domínios específicos versavam sobre o título, objetivos de aprendizagem, integração entre os conteúdos, estrutura e apresentação e relevância. Para isso, seguiu-se os seguintes parâmetros: 1- inadequado (I), 2- pouco adequado (PA), 3- adequado (A) e 4- muito adequado (MA). Ao final 
do instrumento existia um espaço para sugestões que deveria ser preenchido, caso o avaliador atribuísse nota 1 ou 2. Essa etapa ocorreu no período de julho a setembro de 2020, e seguiu os princípios da técnica Delphi (NOGUEIRA VO e CUNHA ICKO, 2018).

Ao obter o consenso dos juízes em determinados itens, os mesmos eram retirados do questionário e os demais revisados e reenviados pelo pesquisador aos especialistas com os resultados obtidos na primeira rodada de sugestões. A partir disso, iniciava-se a segunda rodada de avaliação, e as demais rodadas de sugestões, aconteceram com essa mesma dinâmica até obter o consenso dos juízes em todos os itens, considerando o Índice de Validade de Conteúdo (IVC) igual ou superior a 80\% (SCARPARO AF, et al., 2012).

Após concordância dos juízes, seguiu-se para validação semântica do manual, realizada pelo público-alvo. Foram convidados a participar da pesquisa 10 (dez) estudantes do primeiro período e 10 (dez) estudantes do quinto período do curso técnico em enfermagem de uma Instituição Pública de Ensino. Após o aceite, foram enviados e-mails contendo Termo de Consentimento Livre e Esclarecido - TCLE e o manual, para leitura prévia, aos interessados em participar da pesquisa.

Para validação semântica do manual, realizou- se uma reunião com os estudantes, através da Plataforma Google meet $\Theta$, em que foi disponibilizado o link de acesso ao questionário tipo Likert, através do Google form ${ }^{\circledR}$. Na oportunidade foram avaliados os seguintes critérios: objetivos do manual, organização e estrutura, estilo da escrita e capacidade de estímulo para o estudo. Esses critérios foram julgados através dos parâmetros: 1- inadequado (I), 2- pouco adequado (PA), 3- adequado (A) e 4- muito adequado (MA), ao final do instrumento continha um espaço para sugestões que deveria ser preenchido, caso o avaliador atribuísse a nota 1 ou 2.

Quanto aos objetivos do manual, o público-alvo analisou se o material atende aos objetivos da turma no tocante à aprendizagem do conteúdo; favorece a compreensão dos conteúdos da disciplina de técnicas em enfermagem; sua utilização está adequada para turma do primeiro período do curso técnico em enfermagem.

Com relação a organização e estrutura, verificaram se o manual apresentava: capa atraente e com indicações claras do conteúdo do material; título e conteúdo com tamanho adequado nos tópicos; sequência dos tópicos; capa, contracapa, sumário, agradecimentos e/ou apresentação e/ou introdução tem as informações coerentes; número de páginas adequado.

Em se tratando do estilo de escrita, os estudantes julgaram se o constructo mostra: estilo de escrita adequado para turma; descrição do texto que proporciona excitação e desperta interesse pela resolução do caso; vocabulário acessível e compreensível; que entre o tema e o caso é possível estabelecer uma associação com o problema correspondente; texto claro, de leitura fácil e fluida; estilo de redação que corresponde ao nível de conhecimento da turma a que se destina o manual.

E por fim, quanto a aparência, os estudantes analisaram se as páginas ou seções possuem organização adequada e no âmbito do estímulo para o estudo, eles avaliaram se o material é apropriado para formação de profissionais da área da saúde; apresenta lógica nos conteúdos, problemas e ilustrações; tem interação e induz o interesse pela associação entre teoria e prática; aborda os conteúdos pertinentes ao componente curricular "Técnicas Básicas"; viabiliza o interesse pela formação do profissional de enfermagem através da mudança de comportamento e atitude; proporciona ao estudante o conhecimento necessário para o desenvolvimento da prática, por meio dos conteúdos teóricos; os temas dos casos-problemas atraem o leitor.

Como critério de inclusão, os estudantes deveriam estar devidamente matriculados no primeiro e quinto período do curso técnico em enfermagem, cursando ou concluído o componente curricular "Técnicas Básicas", não estivessem de férias, licença ou indisponível no momento da coleta de dados. Deste modo, participaram do estudo 17 estudantes de curso técnico em enfermagem.

As informações obtidas na coleta de dados, tanto na validação de conteúdo quanto na validação semântica, foram interpretadas e transcritas para planilhas do programa Microsoft Exce®l. No que tange os questionários tipo likert, empregou-se o Índice de Validade de Conteúdo (IVC), que mede a proporção ou percentagem dos juízes que convergiram sobre determinado aspecto do instrumento e seus elementos (ALEXANDRE NM e COLUCI MZO, 2011). 
O cálculo do IVC, referente ao manual em questão, foi realizado pela divisão do número total de juízes que atribuiu pontuação de "3" ou "4" pelo número total de respostas, em uma escala ordinal de quatro pontos com significância de "inadequado" a "muito adequado" (ALEXANDRE NM e COLUCI MZO, 2011). No presente trabalho, diante da participação de mais de 6 juízes nas duas etapas de validação, foi considerado índice de aprovação concordância mínima de 80\%.

A pesquisa foi aprovada em 13 de julho de 2020, por meio do parecer no 4.152.600 Comitê de Ética em Pesquisa da Faculdade Pernambucana de Saúde.

\section{RESULTADO E DISCUSSÃO}

Quanto ao processo de construção do manual, o material desenvolvido foi intitulado "Aprendizagem baseada em problemas: manual de técnicas básicas para curso técnico em enfermagem", é fundamentado em ABP, tem 45 páginas e 13 capítulos que abordam conteúdos pertinentes a técnicas básicas, através da apresentação dos objetivos de aprendizagem, seguidos da situação- problema que abrange um ou mais conteúdos do referido componente curricular (Figura 1).

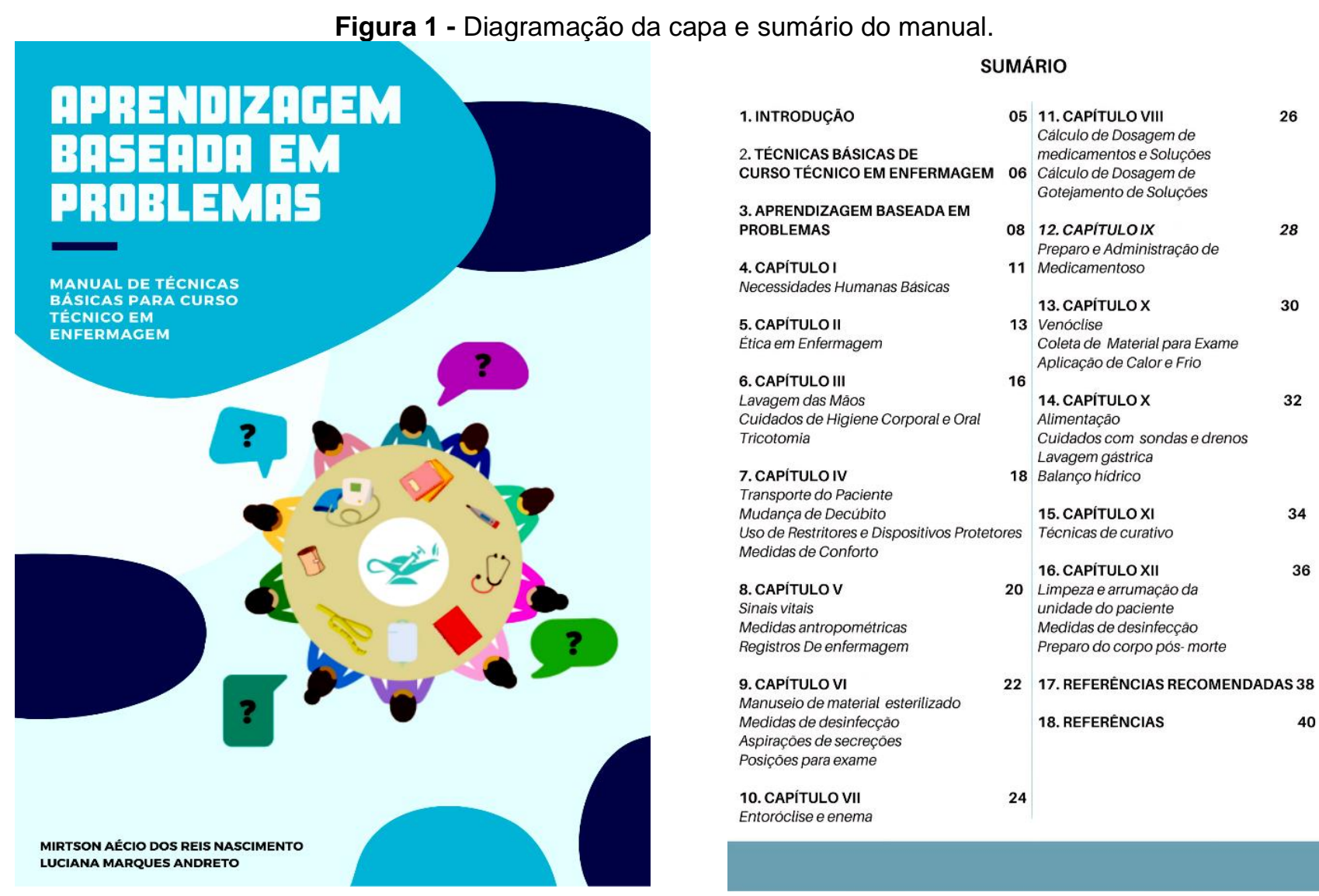

Fonte: Nascimento MAR e Andreto LM, 2021.

No que diz respeito a consulta aos especialistas, foram realizadas três etapas de envio do questionário, no total participaram 10 enfermeiros, dentre esses, 90\% (9) eram docentes de cursos na área de enfermagem, $70 \%$ (7) possuíam mestrado, 10\% (1) doutorado e 20\% (2) eram especialistas. Os experts apresentaram pontuação de 24,0 a 74,0, conforme os critérios de seleção apresentados anteriormente.

Observa- se que os capítulos II, IV, V, VI, VII, XI e XIII obtiveram consenso na primeira rodada, enquanto os capítulos I, III, X e XII, na segunda e, por fim, os capítulos VIII e IX, foram aprovados na terceira rodada. O capítulo I apresentou os menores índices (88,8 \%), no que tange os aspectos avaliados, enquanto os capítulos II, VI, VIII, IX e XI obtiveram os valores máximos (100\%). A média global do IVC foi de $97,68 \%$, ratificando a validação do conteúdo junto aos especialistas (Tabela 1). 
Tabela 1 - Julgamento dos juízes para avaliação das situações-problema do Manual para Técnicas Básicas Fundamentado em Aprendizagem Baseada em Problemas. Belo Jardim- PE, 2020.

IVC* (\%)

\begin{tabular}{|c|c|c|c|c|c|c|c|c|}
\hline Capítulos & $\begin{array}{l}\text { Validação por } \\
\text { rodada }\end{array}$ & $\mathbf{n}$ & Título & $\begin{array}{l}\text { Integração entre } \\
\text { os conteúdos }\end{array}$ & $\begin{array}{c}\text { Objetivos } \\
\text { de aprendizagem }\end{array}$ & $\begin{array}{l}\text { Estrutura e } \\
\text { Apresentação }\end{array}$ & Relevância & IVCG** $\left.^{* *}\right)$ \\
\hline I. A teoria que antecede a prática & $2^{\circ}$ & 9 & 88,8 & 88,8 & 88,8 & 88,8 & 88,8 & \\
\hline II. Ter ou não ter ética é a questão & $1^{\mathrm{a}}$ & 10 & 100 & 100 & 100 & 100 & 100 & \\
\hline III. O cuidado de todo dia & $2^{\mathrm{a}}$ & 9 & 100 & 100 & 88,8 & 88,8 & 100 & \\
\hline IV. Só na técnica & $1^{\mathrm{a}}$ & 10 & 100 & 100 & 90 & 90 & 100 & \\
\hline $\begin{array}{l}\text { V. Não é só aferir, tem que saber } \\
\text { medir. Pois anota aí! }\end{array}$ & $1^{\mathrm{a}}$ & 10 & 100 & 100 & 90 & 100 & 100 & \\
\hline $\begin{array}{l}\text { VI. A posição pode fazer toda } \\
\text { diferença }\end{array}$ & $1^{\mathrm{a}}$ & 10 & 100 & 100 & 100 & 100 & 100 & \\
\hline VII. A dúvida do conhecimento & $1^{\mathrm{a}}$ & 10 & 100 & 100 & 90 & 100 & 100 & \\
\hline $\begin{array}{l}\text { VIII. A experiência pode ou não } \\
\text { fazer a diferença }\end{array}$ & $3^{\mathrm{a}}$ & 9 & 100 & 100 & 100 & 100 & 100 & 97,68 \\
\hline $\begin{array}{l}\text { IX. Hoje tem preparo e } \\
\text { administração de medicamento, } \\
\text { vamos praticar? }\end{array}$ & $3^{\mathrm{a}}$ & 9 & 100 & 100 & 100 & 100 & 100 & \\
\hline $\begin{array}{l}\text { X. Alguns cuidados de } \\
\text { enfermagem }\end{array}$ & $2^{\underline{a}}$ & 9 & 100 & 100 & 88,8 & 100 & 100 & \\
\hline $\begin{array}{l}\text { XI. Vias alternativas de entradas e } \\
\text { saídas }\end{array}$ & $1^{\mathrm{a}}$ & 10 & 100 & 100 & 100 & 100 & 100 & \\
\hline XII. O objetivo é cicatrizar & $2^{\mathrm{a}}$ & 9 & 100 & 100 & 88,8 & 100 & 100 & \\
\hline $\begin{array}{l}\text { XIII. Limpeza e organização: uma } \\
\text { mão na roda }\end{array}$ & $1^{\mathrm{a}}$ & 10 & 90 & 100 & 100 & 100 & 100 & \\
\hline
\end{tabular}

Legenda: * Índice de Validade de Conteúdo; ** Índice de validação de conteúdo Global.

Fonte: Nascimento MAR e Andreto LM, 2021. 
Os especialistas também foram consultados acerca de sugestões para o manual, que poderiam ser relacionadas ou não aos itens que obtiveram índice de concordância menor que $80 \%$. Esses comentários foram analisados quanto à sua pertinência para o desenvolvimento e aperfeiçoamento do manual e posteriormente sumarizados por meio de categorias (Quadro 1).

Quadro 1 - Distribuição das categorias de sugestões e comentários dos juízes.

\begin{tabular}{|c|}
\hline Categorias \\
\hline Revisão de português \\
\hline Alterações quanto a estrutura das situações- problemas \\
\hline Retirada de conteúdo do manual \\
\hline Alterações acerca da imagem contida na capa \\
\hline Alterações acerca das imagens contidas no interior do manual \\
\hline Adequação de termos e procedimentos técnicos \\
\hline Adequação dos objetivos de aprendizagem \\
\hline Integração de conteúdos \\
\hline Relevância da produção para formação do técnico em enfermagem \\
\hline Fonte: Nascimento MAR e Andreto $L M, ~ 2021$
\end{tabular}

Fonte: Nascimento MAR e Andreto LM, 2021.

Deste modo, o manual passou por uma revisão textual, por profissional especializado nesta atividade. Quanto as imagens, a capa sofreram as alterações sugeridas, como retirada de seringa com líquido vermelho e curativo adesivo presente sobre a mesa e inserção de personagens negras, bem como femininas, já que os cursos de enfermagem têm predominância desse sexo.

Foram respeitadas as sugestões quanto a integração de conteúdos, na medida em que sua primeira versão possuía 10 capítulos e foram acrescidos três para proporcionar melhor harmonia entre eles. Foram alterados termos e procedimentos técnicos. De acordo com um dos juízes "os problemas trazem várias questões relacionadas ao assunto pretendido e faz ligações com outros assuntos já vistos possibilitando a aprendizagem".

Essas solicitações corroboram com os princípios da ABP, pois a intenção do caso é a promoção da integração dos conteúdos, através de diferentes processos mentais e superando a memorização. Através desse método há de se rever conteúdos, bem como as possibilidades de integração deles (CYRINO EG e TORALLES-PEREIRA ML, 2004)

O manual sofreu alterações quanto a ordem dos capítulos, para acatar a seguinte sugestão, "estabelecendo uma conexão de ciclo de vida começo, meio e fim ", deste modo, optou-se por apresentar os conteúdos de menor aos de maior complexidade, respectivamente. Não foi contemplada a retirada do conteúdo necessidades humanas básicas, tampouco acrescidas outras teorias de enfermagem, visto que se trata de um conteúdo estabelecido no PPC do curso de onde foi extraído o atual conteúdo programático.

No que tange aos objetivos de aprendizagem, foram respeitados os comentários pertinentes a Taxonomia de Bloom. Esse instrumento de planejamento tem colaborado significativamente com o processo de ensino, pois permite a classificação de objetivos de aprendizagem de maneira hierárquica e auxilia na identificação e na declaração dos objetivos ligados ao desenvolvimento cognitivo. Deste modo, pode ser empregado para estruturar, organizar e planejar disciplinas, cursos ou módulos instrucionais (FERRAZ APDCM e BELHOT $R V, 2010)$.

Por fim, verificou-se o reconhecimento da relevância da proposta de aplicar a aprendizagem baseada em problemas, no contexto da formação de técnicos em enfermagem, segundo um dos juízes "Excelente e relevante produção, para contribuir com a formação da maior categoria profissional na saúde, os técnicos em enfermagem". Desta maneira, este produto poderá contribuir com a prática docente, para formação de profissionais críticos, reflexivos e com uma compreensão mais pertinente aos diversos cenários vivenciados pela categoria.

De acordo com Santos EO et al. (2017), a utilização de metodologias ativas no ensino da enfermagem enfatiza a crítica, discussão e troca de conhecimentos, contribui para formação de profissionais 
comprometidos em atuar em diferentes cenários no campo da saúde, facilitando o trabalho em equipe e resolução de problemas. A partir disso, há a formação de um profissional que presta cuidados com embasamento científico, de maneira holística, que considera a singularidade do sujeito.

No que diz respeito a avaliação semântica, 17 estudantes de curso técnico em enfermagem participaram desta etapa, dentre esses $52,9 \%$ (9) eram do primeiro período, e $47,1 \%$ (8) estavam no último período do curso. 94,1\% (16) pertenciam ao sexo feminino, 94,1\% (16) tinham entre 18 e 24 anos.

A análise pertinente ao IVC aponta que apenas os itens "Entre o Tema e o caso: é possível estabelecer uma associação com o problema correspondente" e "Os Temas dos casos-problemas atraem o leitor" apresentaram $94,1 \%$ de concordância, o restante dos domínios avaliados teve $100 \%$ de aceitação. E, de uma maneira geral, o manual obteve uma avaliação satisfatória por parte do público-alvo, com índice geral do instrumento de $99,46 \%$, o que aponta que os itens são compreensíveis e podem ser aplicados de maneira favorável ao contexto a que se destina (Tabela 2).

Tabela 2 - Julgamento dos estudantes $(n=17)$ sobre situações problemas da escala de Likert para avaliação da adequação do Manual para Técnicas Básicas Fundamentado em ABP.

\section{Objetivo}

Itens $\quad$ IVC $^{*}(\%) \quad$ IVCG** $^{* *}$

Atende aos objetivos da turma no tocante à aprendizagem do conteúdo 100

Favorece a compreensão dos conteúdos da disciplina de técnicas em enfermagem 100

Sua utilização está adequada para turma do primeiro período do curso técnico em enfermagem

\begin{tabular}{lc} 
Onfermagem & 100 \\
\hline O Capa é atraente e com indicações claras do conteúdo do material & 100 \\
O Título e o Conteúdo apresentam tamanho adequado nos tópicos & 100 \\
Os tópicos têm sequencia & 100 \\
Você acha que a Capa, contracapa, sumário, agradecimentos e/ou apresentação & \\
e/ou Introdução apresentam informações coerentes & 100 \\
Número de páginas: adequado & 100 \\
\hline Estilo da escrita & 100 \\
\hline Estilo da escrita: adequado para a turma & 100 \\
Descrição do texto: proporciona excitação e desperta interesse pela resolução do & 100 \\
caso. &
\end{tabular}

Entre o Tema e o caso: é possível estabelecer uma associação com o problema correspondente

94,1

Texto: claro, leitura fácil e fluída

100

Estilo da redação: corresponde ao nível de conhecimento da turma a que se destina o manual

\section{9,46}

100

\begin{tabular}{lc}
\hline Aparência & 100 \\
\hline Páginas ou seções: possuem organização adequada & \\
\hline Motivação para estudo & 100 \\
\hline Material: está apropriado para formação de profissionais da área da saúde & 100 \\
Material: apresenta lógica nos conteúdos e problemas. & 100 \\
Interação: induz o interesse pela associação entre teoria e prática & 100 \\
Manual: aborda os conteúdos pertinentes ao componente curricular Técnicas & 100 \\
básicas. & \\
Viabiliza o interesse pela formação do profissional de enfermagem através da & 100 \\
mudança de comportamento e atitude & 94,1 \\
Manual: proporciona ao estudante o conhecimento necessário para o & \\
desenvolvimento da prática por meio dos conteúdos teóricos. &
\end{tabular}


Diante dos resultados apresentados acima, verifica- se que, para o público-alvo desta pesquisa, o manual favorece o processo de ensino aprendizagem dos conteúdos do componente curricular em questão, a partir da possibilidade de viabilizar o interesse pela formação do profissional de enfermagem através da mudança de comportamento e atitude. Além disso, apresenta uma organização e escrita favorável a compreensão dos itens.

Para Borochovicius E e Tortela JCB (2014), na metodologia ABP, os estudantes necessitam refletir e desenvolver habilidades para a resolução dos problemas propostos, estimulando sua capacidade de raciocínio. Além disso, aprendem a utilizar os conhecimentos adquiridos de forma criativa para cada situação específica, e com isso aprimorar suas habilidades em aprender os conteúdos apresentados.

Pesquisa realizada por Vidor SB et al. (2018) aponta que estudantes de veterinária tem dificuldade em conectar conteúdos de aulas teóricas com aqueles de aulas práticas, quando são utilizadas técnicas de ensino tradicionais. E, de acordo com Souza SC e Dourado L (2015) as atividades desenvolvidas em sala de aula precisam estar conectadas com a área de estudo, através dessa condição, os alunos poderão aprender dialogando com a sua futura profissão, tornando-se profissionais ativos capacitados.

Ferramentas de ensino, fundamentadas em ABP, podem contribuir diretamente para a formação de técnicos em enfermagem. Para isto, esses materiais devem apresentar alta confiabilidades. Desta maneira, a participação de peritos e representantes do público-alvo podem proporcionar a credibilidade e aceitação de práticas educativas (TELES LMR et al., 2014).

Além disso, é possível inferir que, para eles, as situações-problema atraem o leitor para resolução dos casos, como também possibilita uma associação entre teoria e prática. Provavelmente, isso deve-se a apresentação de situações fictícias do cotidiano do técnico em enfermagem ou do próprio estudante de curso técnico.

De acordo com Macedo KDS, et al. (2018), as situações-problema (SP) apresentadas ao estudante precisam se aproximar ao máximo do seu cotidiano, contexto familiar, acadêmico ou social, com abordagem de conteúdos essenciais para sua formação profissional. Desta maneira, eles adentram a situação e apresentam o interesse necessário para atingir os objetivos da aprendizagem. O estudo é realizado de forma coletiva e posteriormente discutido em grupo, possibilitando uma aprendizagem colaborativa, criativa, critica e reflexiva, reduzindo a fragmentação do aprendizado.

A SP, que inicia o processo de aplicação da ABP, apresenta um cenário que, na maioria das vezes, não possui todas as informações necessárias para a sua solução. Diante dessa problemática, surge uma série de questionamentos sem respostas imediatas, que deverão ser investigadas pelos alunos (LOPES RM, et al., 2019).

Considerado apropriado para formação de profissionais da área da saúde este manual poderá contribuir com a formação dos profissionais em questão, além de reforçar a importância da prática de metodologias ativas nesse contexto profissional. A construção de materiais didáticos, que proporcionem uma formação integral do profissional de enfermagem, torna-se cada vez mais necessária, para aproximar a teoria educacional a prática profissional. Essa metodologia leva o estudante para além das suas expectativas ao inserir, no seu processo de ensino, exemplificações concretas do mundo profissional (SILVA ES et al., 2019).

\section{CONSIDERAÇÕES FINAIS}

Após o cumprimento das etapas metodológicas para validação do manual para técnicas básicas de curso técnico em enfermagem, verifica- se que a avaliação juízes e representantes do público-alvo, possibilitou o aprimoramento do material elaborado e, realizadas as modificações sugeridas, a versão final do material foi considerada válida quanto à aparência e conteúdo. O impacto do manual educativo na aprendizagem dos estudantes de cursos técnicos em enfermagem não pôde aqui ser mensurado, constituindo objeto de estudo posterior. 


\section{REFERÊNCIAS}

1. ALEXANDRE NM, COLUCI MZO. Validade de conteúdo nos processos de construção e adaptação de instrumentos de medidas. Ciên e Saúde Col, 2011; 16(7): 3061-68.

2. BALTAZAR C. Educação, trabalho e o curso técnico de enfermagem do Instituto Federal da Bahia - IFBA / Campus Eunápolis. In: SANTANA DSS, et al. (Orgs.). Prosas (Im)pertinentes: Educação e outros temas. Eunápolis: Núcleo de Estudos em Educação Profissional (NEEP), 2020; 88-108.

3. BOROCHOVICIUS E, TORTELLA JCB. Aprendizagem Baseada em Problemas: um método de ensinoaprendizagem e suas práticas educativas. Ensaio: Avaliação e Políticas Públicas em Educação, $2014 ; 22$ (83): 263 94.

4. BRASIL. Lei n. 7.498/86, que dispõe sobre o exercício da enfermagem e dá outras providências. Brasília; 1987.

5. CARVALHO NETO FJ. Aplicação do método aprendizagem baseada em problemas no ensino de auditoria em enfermagem. In: BARBOSA SRMB (Org.). A enfermagem e o gerenciamento do cuidado integral 5. Ponta GrossaPR: Atena, 2020; 61-70.

6. CYRINO EG, TORALLES-PEREIRA ML. Trabalhando com estratégias de ensino-aprendizado por descoberta na área da saúde: a problematização e a aprendizagem baseada em problemas. Cadernos de Saúde Pública, 2004; 20: 780-788.

7. DANTAS RAS, AGUILLAR OM. O ensino médio e o exercício profissional no contexto da enfermagem brasileira. Rev. Latino-am. Enfermagem, Ribeirão Preto, 1999: 7(2). 25-32

8. ESCRIVÃO FE, RIBEIRO LRC. Aprendendo com PBL- Aprendizagem Baseada em Problemas: relato de uma experiência em cursos de engenharia da EESC-USP. Revista Minerva: pesquisa e tecnologia. São Carlos, 2009; 6(1):23-30.

9. FEHRING R. The Fehring Model. In: Carrol-Johnson R, Paquete M, editores. Classification of nursing diagnoses: proceedings of the tenth conference of North American Nursing Diagnosis Association. Philadelphia: Lippincott, 1994; 55-62.

10. FERRAZ APDCM, BELHOT RV. Taxonomia de Bloom: revisão teórica e apresentação das adequações do instrumento para definição de objetivos instrucionais. Gestão \& Produção, 2010; 17(2): 421- 31.

11. IFPE. Instituto Federal de Educação, Ciência e Tecnologia de Pernambuco. Projeto Pedagógico do Curso Técnico em Enfermagem, campus Belo Jardim. 2018

12. LOPES RM, et al. Características gerais da aprendizagem baseada em problemas. IN: LOPES RM. et al. Aprendizagem baseada em problemas: fundamentos para a aplicação no ensino médio e na formação de professores. 1a ed. Rio de Janeiro: Publik, 2019; 198p.

13. MACEDO KDS, et al. Metodologias ativas de aprendizagem: caminhos possíveis para inovação no ensino em saúde. Escola Anna Nery, 2018; 22 (3): 1-9.

14. NOGUEIRA VO, CUNHA ICKO. Validação de conteúdo do perfil de competências de enfermeiros gestores de ensino superior. Rev. Cuid, 2018; 9 (1): 1998-2006.

15. RODRIGUES CCFM, et al. Ensino inovador de enfermagem a partir da perspectiva das epistemologias do Sul. Escola Anna Nery, 2016; 20(2): 384-389.

16. SCARPARO AF, et al. Reflexão sobre o uso da técnica de Delphi em pesquisas na enfermagem. Rev Rene, 2012; 13(1): 242-51.

17. SANTOS EO. Aprendizagem baseada em problemas no ensino da enfermagem. Revista Contexto \& Saúde, 2017; 17(32): 55-66.

18. SILVA ES, et al. Aprendizagem baseada em problema aplicada no ensino de urgência e emergência na enfermagem: um relato de experiência/Learning based on a problem applied in emergency and nursing education in nursing: an experience report. Brazilian Journal of Health Review, 2019; 2(4): 2525-2529.

19. SIQUEIRA-BATISTA R, SIQUEIRA-BATISTA R. Os anéis da serpente: a aprendizagem baseada em problemas e as sociedades de controle. Ciência \& Saúde Coletiva, 2009; 14:1183-1192.

20. SOBRAL FR, CAMPOS CJG. Utilização de metodologia ativa no ensino e assistência de enfermagem na produção nacional: Revisão integrativa. Rev. esc. enferm. USP, 2012; 46 (1): 208 - 18.

21. SOUSA CEGC. Metodologias ativas de ensino aprendizagem na área da saúde: revisão de literatura. Facit Business and Technology Journal, 2020; 1(21: 51- 62.

22. SOUZA ACD, et al. Propriedades psicométricas na avaliação de instrumentos: avaliação da confiabilidade e da validade. Epidemiol. Serv. Saude, 2017; 26 (3): 649-59.

23. SOUZA SC, DOURADO L. Aprendizagem baseada em problemas (ABP): um método de aprendizagem inovador para o ensino educativo. Holos, 2015; 5 (31):182-200.

24. TELES LMR, et al. Construção e validação de manual educativo para acompanhantes durante o trabalho de parto e parto. Rev Esc Enferm USP, 2014; 48 (6): 977- 84.

25. TEIXEIRA JS, et al. Utilização de metodologias ativas em um curso técnico em enfermagem: relato e desafios. Revista Com Censo: Estudos Educacionais do Distrito Federal, 2017; 4 (4): 176 - 80.

26. VIDOR SB, et al. Aprendizagem baseada em problemas: integrando a prática com a teoria no ensino da medicina veterinária. Revista docência do ensino superior, 2018; 8(2): 195-210. 